\title{
Tourism employment and local residents' engagement in the conservation of the built heritage in Zanzibar Stone Town in Tanzania
}

\author{
N. B. Lwoga \\ University of Dar es Salaam, Tanzania
}

\begin{abstract}
This study investigated the moderating effect of tourism employment on the relationship between attitudes to conservation, perceived social pressure, and perceived control on one hand, and intention to conserve built heritage on the other. This was an attempt to extend the theory of planned behaviour (TPB) which has been widely applied in conservation studies without integrating tourism factors that may exert effects on the relationships. A questionnaire survey was applied to 208 households in Zanzibar Stone Town. The results of the structural model verify the effect of attitudes, perceived social pressure and perceived control on intention to conserve. They also indicate that tourism employment significantly moderated the attitudes-intention and perceived social pressure-intention relationships. Overall, the study supports the extension of TPB with the inclusion of tourism employment as an important situational factor. Theoretical, policy and managerial implications are discussed.
\end{abstract}

Keywords: tourism employment, conservation, resident, heritage, Zanzibar.

\section{Introduction}

The importance of local residents' engagement in conservation in achieving sustainable heritage management has attracted studies [1-3], into examining the factors that influence engagement in conservation. The most noted influence emanates from personal and situational factors Barr [1], McDonald [4]. Personal factors include attitudes, and perceptions Kaiser et al. [3], whereas situational factors include the socio-cultural and economic context of conservation areas Kollmuss and Agyeman [5]. A few studies [3, 6], have considered that either personal or situational factors cause local residents to engage in conservation, 
but this appears to provide a limited understanding of engagement in conservation, which has been noted to be influenced by personal factors as well as situational factors. Interestingly, despite the fact that conservation areas are being developed for tourism, the role of tourism factors in explaining engagement in conservation has received limited research attention.

This study attempted to fill the knowledge gap by integrating sociopsychological factors, which have been widely acknowledged as influencing individual behaviour, and situational factors, especially tourism employment status of local residents to gain a better understanding of engagement in conservation. By adapting the theory of planned behaviour (TPB) and integrated conservation and development project (ICDP) model, a conceptual model was developed and tested with the socio-psychological variables such as attitude to conservation, and perceived social pressure and perceived control as antecedents to intention to conserve. Tourism employment was treated as a moderating variable in the relationship between socio-psychological variables and intention to conserve.

The global emphasis on the ICDP, and the changing economic trends involving the rapid growth of tourism, makes it important to understand the role of tourism in conservation. In contexts other than sub-Sahara Africa, Lundberg [7] argued that tourism relates to local residents' support for tourism. However, limited studies $[8,9]$, related tourism factors with engagement in conservation; moreover in natural park setting. McKenzie-Mohr and Schultz [10] noted that the focus on solely the economic advantages of engaging in a particular act has failed to foster desired behaviour. Thus, understanding the roles of tourism employment within the foundations of TPB is indeed central to this study, and contributes to empirical evidence about the tourism-conservation relationship. An insight into the effect of tourism employment on the TPB model may reveal alternative strategies to heritage managers as they work on fostering public participation in conservation. In seeking to fill the knowledge gap this study was guided by the following research questions: What is the impact of sociopsychological factors (attitudes to conservation, perceived social pressure and perceived control) on intentions to conserve? Does tourism employment status have an effect on the relationship between socio-psychological factors on the one hand, and intentions to conserve on the other?

\section{Conceptual foundation}

\subsection{Theory of planned behaviour}

The theory of planned behaviour (TPB) provides an explanatory perspective on person's engagement in a particular act. It assumes that the stronger the intention to engage in an act, the more likely its performance Ajzen [11]. The intention is defined as willingness to act in a particular way (Fishbein and Ajzen [12]). Thus, intention to conserve is defined as the person's willingness to engage in actions that contribute to the maintenance of the fabric, structure and setting of the built heritage (Lwoga et al. [13]). The TPB further maintains that attitudes to 
behaviour and perceived social pressure positively relate to intention. While attitude refers to the degree to which a person has a favourable or an unfavourable evaluation of the act in question, perceived social pressure refers to a person's belief about whether significant others think that he or she should engage in the act (Ajzen [11]). The TPB also considers actions not under volitional control, and depend on such non-motivational factors as availability of opportunities and resources (Ajzen [11]). This idea is expressed in the construct known as perceived control, which is defined as one's perception of how easy or difficult it is to perform the act. The theory posits that perceived control predicts intentions in such acts such as engagement in conservation with limited volitional control. Despite its usefulness, the TPB is criticized for focusing on a person's cognitive evaluation of the act in question that limits its scope for explaining behaviours (Lwoga et al. [13]). Consequently, studies [14, 15], proposed that additional variables should be included in the TPB. With this regard, it is acknowledged that situational factors are important in explaining conservation acts (Barr [1] and Barr and Gilg [14]), but these factors relating to tourism have barely been added to the TPB.

\subsection{Integrated conservation and development project}

Integrated conservation and development project (ICDP) is an approach by Wells et al. [16], based on the incentive theory by Skinner [17], which posits that people will conserve resources when they have an incentive to do so. Economic incentives, especially tourism employment opportunities, have been widely reported in studies [9, 18, 19], to influence residents' engagement in conservation. Most conservation areas in the world struggle to provide economic incentives to residents, taking tourism employment as a tool (Snyman [6]). Tourism employment is reflected by person's direct employment (or selfemployment) in tourism (Stem et al. [8]).

\section{Research hypotheses}

Past studies [3, 20], have embarked on efforts to elucidate the influence of attitudes, perceived social pressure and perceived control on intention to conserve. Kaiser et al. [3] found that attitudes, perceived social pressure and perceived control have significant influence on intentions. Clark and Finley [20] also found that attitude, perceived control and perceived social pressure have significant relationship with intention to conserve. Abrahamse and Steg [21] indicated that only attitude and perceived control have significant relationships with intention to conserve. Tonglet et al. [22] found that attitude is the only factor with a significant relationship to intention. Garrod et al. [2] found that residents would like to contribute towards conservation, but did not afford to. In sub-Saharan Africa, a qualitative exploratory study by Kankpeyeng [23] found that residents were pressured by the community to conform to the village norms and to use traditional materials for repairing their houses. Napon and Rakotomamonjy [24] found that limited access to traditional building materials 
hindered engagement in conservation. It is therefore hypothesized that; there is a positive relationship between the attitudes to conservation and intention to conserve (H1), there is a positive relationship between perceived social pressure and intention to conserve ( $\mathrm{H} 2)$, and there is a positive relationship between perceived control and intention to conserve (H3).

Studies have tried to link tourism employment with conservation. Stem et al. [8] found that, residents who were directly employed in tourism engaged in conservation, while those who were not, did not engage in conservation. Stronza [9] found that tourism employment variable matters in explaining conservation than mere income from tourism dividends. It is thus logical to assume that tourism employment status can amplify the relationship between conservation attitudes and perceptions on the one hand, and intention to conserve on the other. Using the heritage setting where the moderating relationships have yet to be tested would thus contribute to the empirical evidences about the role of tourism in conservation. It is therefore hypothesized that: a positive relationship between attitudes to conservation and intention to conserve is more stronger for residents who are directly employed in tourism than for those who are not (H4); A positive relationship between perceived social pressure and intention to conserve is more stronger for residents who are directly employed in tourism than for those who are not (H5); and positive relationship between perceived control and intention to conserve is more stronger for residents who are directly employed in tourism than for those who are not (H6).

\section{Methods}

Data were gathered from households in Zanzibar Stone Town in Tanzania. The town is a world heritage site situated in the west of Zanzibar Island (figure 1). It is the commercial and political centre of the Island. The main economic activities centre on tourism based on built heritage which evidence the African, Arabic, Asiatic and European cultures (Zanzibar Commission for Tourism (ZCT) [25]). In 2014 , tourism directly employed about 15,000 people, attracted 151,743 tourists in 2013, and resulted to 56 hotels and over 150 local tour operators (ZCT [25]). The sample unit for the study was a household which was considered a group of one or more people living together in a same dwelling, making common provisions for living arrangements (Snyman [6]). Zanzibar Stone Town had 2,396 households scattered in 4 shehias (township wards) of Shangani, Mkunazini, Kiponda and Malindi (URT [26]). According to Hair et al. [28], a minimum sample required in structural modelling is 200, thus a sample of 208 used in the study was adequate. Stratified random sampling was applied to stratify households at the level of shehia in order to ensure that households geographically scattered were represented. The size of the sample drawn from each shehia was proportional in its size to the population. A simple random sampling was then employed to draw a proportional number of households from each shehia. Household registers in the sheha's (chairperson) office were used to randomly pick households. One member from each selected household, preferably, the household head was involved. Data collection was done through a 
researcher-administered questionnaire for three weeks. Households were approached by the researcher and trained assistant during the day at their premises. After introducing the study objectives, the potential respondent's consent in participating in the study led to the conduct of the interviews.

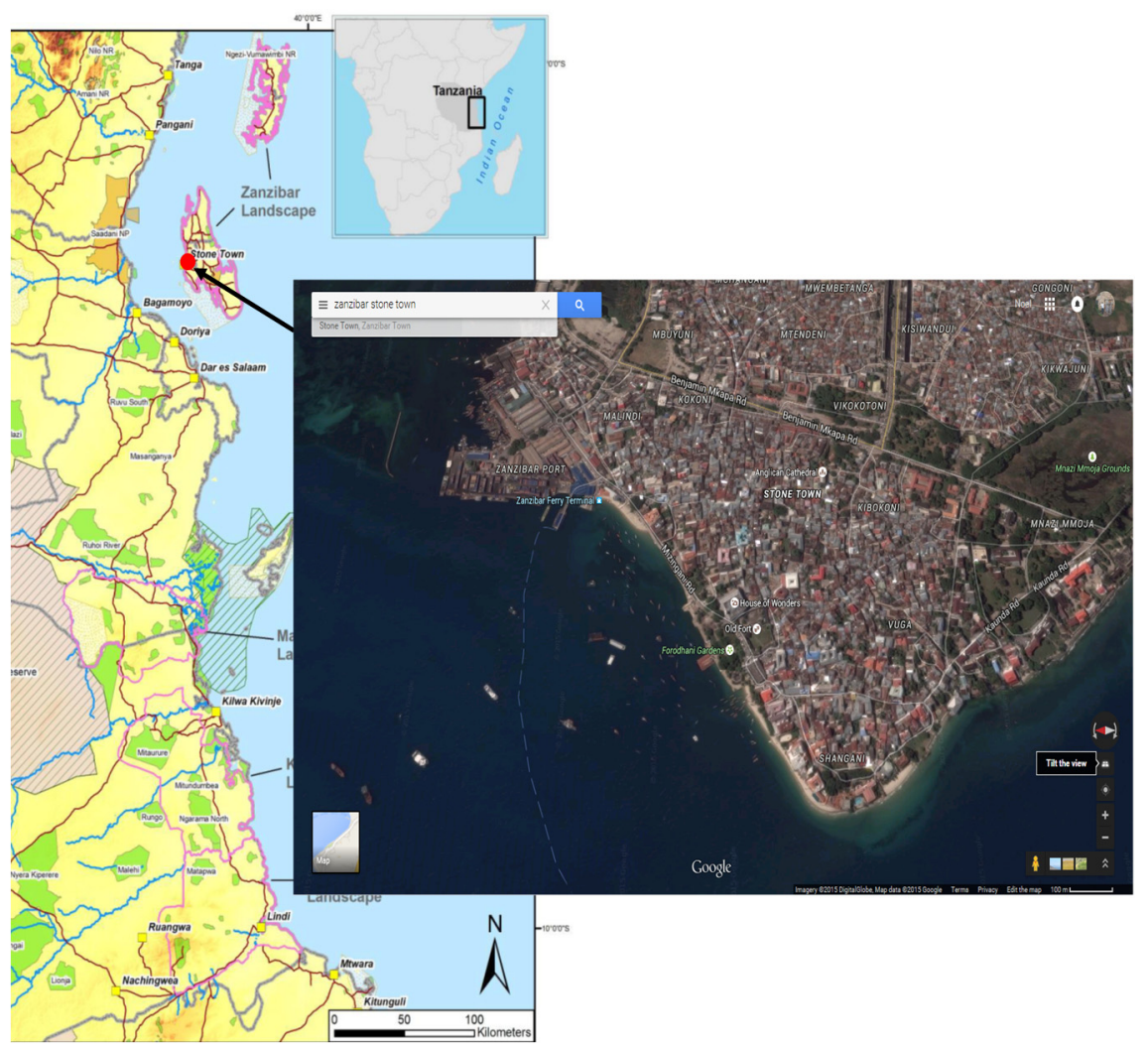

Figure 1: Zanzibar Stone Town (source: Google Map.)

The questionnaire captured attitudes, perceived social pressure, perceived control, intention to conserve, tourism employment status, and demographic characteristics such as age, gender, income, education and occupation. All items with the exception of the demographic items and tourism employment status were framed in a 5-point Likert-type scale with 1 indicating disagreement and 5, agreement. Attitude items were adopted from various studies [15, 22]. Perceived social pressure items were adopted from various studies $[15,20,22,28]$. Perceived control items were adopted from Tonglet et al. [22]. Intention items were adopted from various studies $[2,14]$. Tourism employment measurement was adopted from Stem et al. [8]. All measurement items are presented in appendix. The items that were in English were translated into Swahili and then back-translated into English by professional translators. The items were purified by 11 experts. Next, a pilot test was undertaken. 


\section{Results}

The analysis of respondents' demographics indicated $31 \%$ to be female. With respect to marital status, $75 \%$ were married, $19 \%$ were single, while $6 \%$ were other categories [divorced and widow(er)]. As for educational achievement, only $16 \%$ had attained a university degree; $77 \%$ had obtained primary and secondary education, and $7 \%$ had not gone to school. In terms of monthly household income, 9\% earned above Tshs 1,000,000, the majority (81\%) earned less than Tshs 1,000,000, while 10\% had no income. Age-wise, $22 \%$ were aged between 18 and 30 years, 64\% were aged between 31 and 60 years, and $15 \%$ were aged above 60 years. In terms of employment in tourism, $32 \%$ were directly employed in tourism while $68 \%$ were not.

Data screening was conducted. There were no items which violated the skewness and kurtosis thresholds. An investigation of normal-probability plots, residual scatter plots, and scatter matrices showed no violations of multivariate normality and linearity. SPSS and AMOS were used to test validity. Mean values ranged from 3.57 to 4.27 , table 1 . Cronbach's alpha values were above the cutoff of 0.70 (Nunnally [30]), indicating that the items were internally consistent. A Confirmatory Factor Analysis (CFA) was conducted. The measurement model reasonably fit the data $\left(\chi^{2}=92.227, d f=48, p<0.01\right.$, RMSEA $=0.06, \mathrm{CFI}=$ 0.98 ), and standardized loadings were significant, table 1. Average variance extracted (AVE) values surpassed the cutoff of 0.50 (Fornell and Larcker [31]). The squared correlation between a pair of variables was less that the AVE values. Thus, convergent and discriminant validity were established.

Table 1: Mean, standard deviation, reliability and measurement model results.

\begin{tabular}{|l|l|l|l|l|l|l|l|l|l|}
\hline & Items & Mean & SD & $\boldsymbol{\alpha}$ & IC & AC & PS & PC & TE \\
\hline IC & 3 & 3.63 & 0.94 & 0.83 & 1 & & & & \\
\hline AC & 4 & 4.27 & 0.70 & 0.92 & $0.51^{* * a}\left(0.26^{b}\right)$ & 1 & & & \\
\hline PS & 3 & 3.64 & 0.76 & 0.93 & $0.47^{* *}(0.22)$ & $0.31^{* *}(0.10)$ & 1 & & \\
\hline PC & 2 & 3.57 & 0.98 & 0.85 & $0.54^{* *}(0.29)$ & $0.40^{* *}(0.16)$ & $0.28^{* *}(0.08)$ & 1 & \\
\hline TE & & & & & $0.32^{* *}$ & $0.13^{* *}$ & $0.22^{* *}$ & $0.13^{* *}$ & 1 \\
\hline AVE & & & & & 1.147 & 1.215 & 0.912 & 1.180 & \\
\hline
\end{tabular}

Fit indices: $\chi^{2}=92.227(d f=48, p<0.01), \mathrm{RMSEA}=0.06$ (PCLOSE $\left.>0.05\right), \mathrm{CFI}=0.98, \mathrm{TLI}=0.97$ $\mathrm{SD}-$ standard deviation, $\alpha=$ Cronbach's alpha, ${ }^{\text {a }}$ Correlations, ${ }^{\mathrm{b}}$ Squared correlations, $\mathrm{IC}=$ intention to conserve, $\mathrm{AC}=$ attitudes to conservation, $\mathrm{PS}=$ perceived social pressure, $\mathrm{PC}=$ perceived control.

Hypotheses 1, 2 and 3 were tested using structural equation modelling (SEM) with a maximum likelihood estimation method, which accounted for measurement errors, as well as the interrelationships between constructs. Results verified the fit of the model to the data $\left(\chi^{2}=92.227, d f=48, p<0.01\right.$, RMSEA $=$ $0.06, \mathrm{CFI}=0.98, \mathrm{TLI}=0.97, \mathrm{GFI}=0.934)$. The hypotheses were supported in that significant relationships were found between, intention on the one hand, and attitudes $(\beta=0.31, p<0.001)$, perceived social pressure $(\beta=0.25, p<0.001)$, and perceived control $(\beta=0.44, p<0.001)$ on the other. These variables accounted for $58 \%$ of the total variance for intention (figure 2). Before testing 
the moderation effect, grouping (employed [67 cases] and not employed [141 cases]) was first done. Next, a measurement invariance test was done. Nonrestricted models showed a good fit to the data $\left(\chi^{2}=156.940, d f=96, p<0.01\right.$, RMSEA $=0.056)($ table 2$)$. The model was compared with full-metric invariance model in which all factor loadings were fixed to be equal. Findings revealed that the full-metric invariance was supported $\left(\Delta \chi^{2}(8)=18, p>0.01\right)$ (table 2$)$.

Table 2: $\quad$ Results of the measurement invariance.

\begin{tabular}{|l|l|l|l|l|l|l|l|}
\hline Models & $\chi^{2}$ & $d f$ & RMSEA & CFI & NFI & TLI & RMR \\
\hline Nonrestricted model & 156.940 & 96 & 0.056 & 0.966 & 0.919 & 0.953 & 0.044 \\
\hline Full metric invariance of CFA model & 175.419 & 104 & 0.058 & 0.960 & 0.909 & 0.950 & 0.056 \\
\hline
\end{tabular}

Chi-square difference test: $\Delta \chi^{2}(8)=18.479, p>0.01$ (insignificant) (metric invariance is supported).

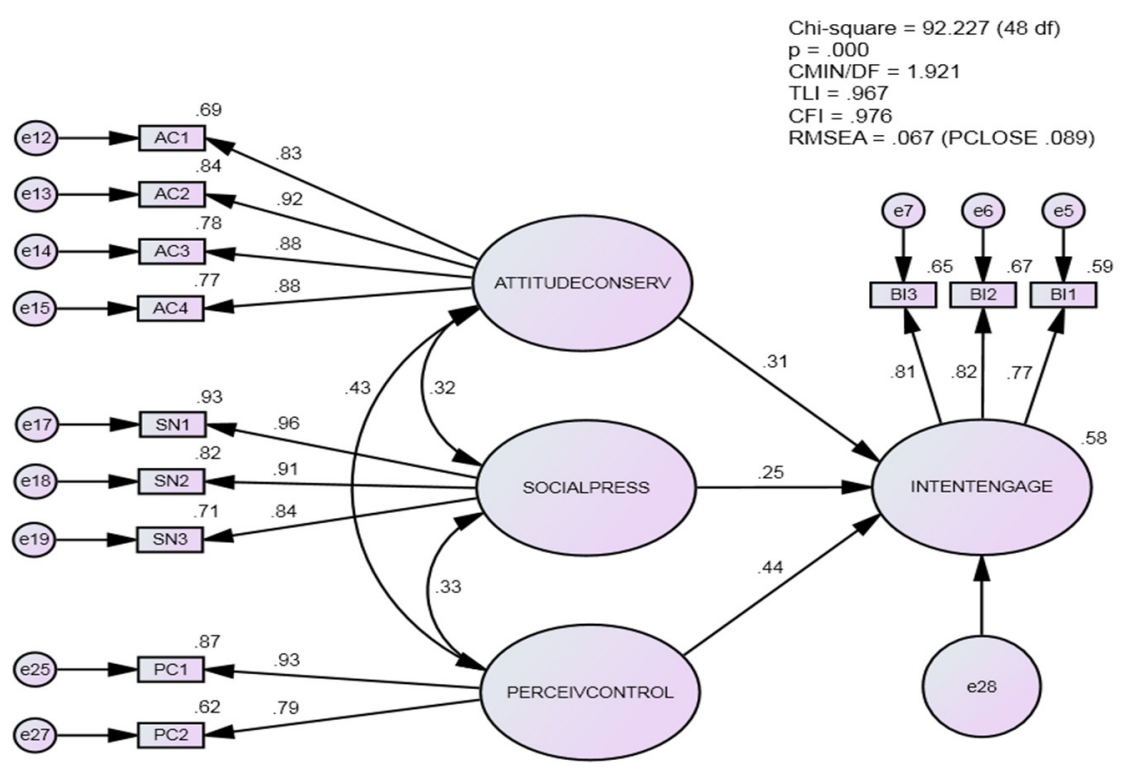

Figure 2: A structural model (standardized estimates).

To test the moderating role of tourism employment status, a structural invariance test was conducted. A baseline model was generated by adding paths among variables rooted in full-metric invariance model. The baseline model demonstrated the adequate fitness to the data $\left(\chi^{2}=156.940, d f=96, p<0.01\right.$, RMSEA $=0.056$ ) (table 3 ). The model was compared to the constrained model. Findings showed that full-structural invariance was supported $\left(\Delta \chi^{2}(11)=\right.$ 26.457, $p<0.01$ ), verifying that tourism employment status significantly moderates relationships among attitudes, perceived social pressure and control, and intention to conserve. Specifically, the positive relationship between attitudes and intention to conserve is significant among respondents who are not employed in tourism $(\beta=0.33, p<0.001)$, and was insignificant to those employed in tourism $(\beta=0.20, p>0.05)$. The positive relationship between 
perceived social pressure and intention to conserve was stronger and more significant to respondents employed in tourism $(\beta=0.31, p<0.01)$ than to those not employed in tourism $(\beta=0.17, p<0.05)$. In regard to the relationship between perceived control and intention, there is a trivial change in the strength of the relationship between the two groups $(\Delta \beta=0.08)$ with no change in statistical significance.

Table 3: Results of the structural invariance.

\begin{tabular}{|l|l|l|l|l|l|l|l|}
\hline Models & $\chi^{2}$ & $d f$ & RMSEA & CFI & NFI & TLI & RMR \\
\hline Full metric invariance & 156.940 & 96 & 0.056 & 0.966 & 0.919 & 0.953 & 0.046 \\
\hline Full Path Invariance & 183.397 & 107 & 0.059 & 0.957 & 0.905 & 0.948 & 0.078 \\
\hline & Employed group & \multicolumn{7}{l|}{ Not employed group } & \\
\hline IC <--- AC & 0.20 & \multicolumn{7}{|l|}{$0.33^{* * *}$} \\
\hline IC <--- PS & $0.31^{* *}$ & $0.48^{* * *}$ \\
\hline IC <--- PC & $0.40^{* * *}$ &
\end{tabular}

Chi-square difference test: $\Delta \chi^{2}(11)=26.457, p<0.01$ (significant) (paths across two groups are significantly different), $* * * p<0.001, * * p<0.01, * p<0.05$.

\section{Discussion}

In contrast to the past research, this study examined the relationships between intention to conserve on the one hand, and attitudes, and perceived social pressure and control on the other, with tourism employment status as a moderator of the relationships. As expected, the study found that sociopsychological variables had significant relationships to intention to conserve, thereby supporting the first, second and third research hypotheses. Perceived control had the strongest relationship to intention to conserve $(\beta=0.44, p<$ $0.001)$, followed by attitudes to conservation $(\beta=0.31, p<0.001)$, and perceived social pressure $(\beta=0.25, p<0.001)$. These results corroborate past research focused on the natural environment $[3,21]$. These results from a built heritage setting add to the empirical evidences that perceived control remains the most influential factor to local residents' intention to conserve. In Zanzibar, the availability of resources and know-how compose key issues that local residents consider before engaging in conservation (Lwoga et al. [13]). Lack of conservation resources, especially lime and mangrove poles can be a general problem of the study setting. Coral reefs and mangrove forests are today preserved along the coast of Tanzania, and are therefore difficult to obtain as construction materials. They are deemed to be very expensive in comparison to the modern construction materials. Moreover, disposable income of the majority of local residents is on average lower, and can hardly be spent on conservation.

According to the study, attitude involves an individual's judgement that conservation is good, useful, rewarding and sensible. It is evident that Zanzibar has a promising tourism sector that provides a leading source of foreign currency for the government. Specifically, prevailing initiatives to involve local residents in tourism through stakeholders' forums help to foster positive attitudes. In terms of perceived social pressure, the results in this study imply that, a local resident is likely to have conservation intentions if she or he believes that important 
others either think she or he should engage in conservation or support conservation. The results support a qualitative study by Kankpeyeng [23]. Previous ethnographic and archaeological evidence related to the study setting supports the view that the ancestors of the present-day Swahili towns may have built many of the heritage assets (Kusimba [32]). Some historic buildings are considered by local residents as sacred sites (Lwoga et al. [13]). This sociocultural context provides the basis to argue that there exists some kind of social pressure from family and particular communities to conserve. Another way to understand the results is from the legislative perspective. Zanzibar Stone Town is a world heritage site where conservation rules and regulations set by global, central and local conservation bodies prevail. Thus, conservation has become a norm that people believe that others either conserve, or expect them to conserve.

The study also, as expected, found that tourism employment status does negatively moderate the relationship between attitudes and intention to conserve, and positively moderate the relationship between perceived social pressure and intention. However, it does not cause any considerable change in the relationship between perceived control and intention. Perhaps, the control and affordability remains key issues of concern in residents' decision to engage in conservation regardless of their tourism employment status. However, the differences in the attitude - intention relationship between those employed in tourism and those who are not is surprising. However, in impoverished towns, it can make intuitive sense that those employed in tourism directly utilize built heritage to earn their living, and thus, to them benefiting from heritage existence is not an issue in their decision to conserve. On the other hand, those who are not directly employed in tourism receive less or no direct tourism economic benefits as compared to their employed counterparts; hence it is more likely for them that benefiting from heritage could be an issue of concern in their decision to conserve. The differences in intention to conserve - perceived social pressure between those employed in tourism and those who are not is also not unexpected, given that those employed do directly utilise, and benefit from, built heritage; and they would be more sensitive about public's concern over their engagement in conservation than their counterparts.

\section{Conclusion and implications}

Conservation of the built heritage presents a serious challenge in Tanzania and related countries. Local residents' engagement in conservation is key to sustainable conservation; however, to achieve this, a thorough understanding of the factors behind their engagement is required. Integrating TPB and ICDP with a sample of households in Zanzibar Stone Town has provided valuable insights into the factors which encourage engagement. The study shows that perceived control over conservation has the strongest relationship with conservation intentions, followed by attitudes to conservation and perceived social pressure. The relationship between perceived social pressure and intentions was stronger among those who were employed in tourism than those who were not. Interestingly, the relationship between attitudes and intentions was stronger 
among those who were not employed in tourism than those who were. The results showed that conservation intention is influenced by both personal and situational factors, and further contributes to empirical evidence on the link between tourism and conservation in the built heritage setting.

Theoretically, the study affirms the utility of the extended TPB with the inclusion of tourism employment as a moderator. In conjunction with past studies that treated tourism employment to be antecedent to conservation, this study indicates tourism employment can be considered as a moderator. The application of multivariate analyses enabled the examination of the relationships in a built heritage setting; some advanced in past qualitative studies in Africa.

The tourism policy of 2005 for Zanzibar emphasizes on raising public's awareness of heritage. While raising awareness is important, the policy should now emphasize on changing attitudes and perceptions, and on promoting tourism employment. The study also offers several recommendations to heritage managers. First, they should elevate positive attitudes by generating, communicating and channelling conservation benefits to local residents. More attention can be directed to residents who are not employed in tourism. Second, they should stimulate societal pressure to conserve by; alerting residents that the heritage belongs to them, involving groups of people which are highly cohesive (e.g. religious leaders) in conservation and, promoting conservation as a social norm. The strategies can particularly shape conservation intentions among tourism employees. Third, they should empower residents in terms of conservation funding, knowledge and skills. Lime-making centres can for instance help in providing conservation materials and skills.

Future studies should consider the diverse types and nature of tourism employment (e.g. whether full-time or part-time) which might impact conservation attitudes and perceptions. They should also account for a common method bias because the use of questionnaire survey is not free from bias.

\section{Appendix}

\begin{tabular}{|l|l|}
\hline \multicolumn{2}{|l|}{ Intention to conserve } \\
\hline BI1 & Willingness to spend my money in activities related to the conservation of built heritage \\
\hline BI2 & Willingness to help others to learn about values of built heritage \\
\hline BI3 & Willingness to report to conservation authorities any unsympathetic activity \\
\hline Attitude towards conservation \\
\hline AC1 & Conservation of built heritage is good \\
\hline AC2 & Conservation of built heritage is useful \\
\hline AC3 & Conservation of built heritage is rewarding \\
\hline AC4 & Conservation of built heritage is sensible \\
\hline Perceived social pressure \\
\hline SN1 & Most people who are important to me think that I should conserve built heritage \\
\hline SN2 & $\begin{array}{l}\text { Most people who are important to me would approve me participating in activities related } \\
\text { to the conservation of built heritage }\end{array}$ \\
\hline SN3 & $\begin{array}{l}\text { I support conservation of built heritage because most people who are important to me do } \\
\text { support conservation }\end{array}$ \\
\hline Perceived control \\
\hline PC1 & I have opportunities and resources to engage in the conservation of built heritage \\
\hline PC2 & I know how to conserve built heritage \\
\hline
\end{tabular}




\section{References}

[1] Barr, S., Factors influencing environmental attitudes and behaviours: A UK case study of household waste management. Environment and Behaviour, 39(4), pp. 435-473, 2007.

[2] Garrod, G.D., Willis, K.G., Bjarnadottir, H. \& Cockbain, P., The nonpriced benefits of renovating historic buildings: A case study of Newcastle's Grainger Town. Cities, 13(6), pp. 423-430, 1996.

[3] Kaiser, F.G., Schultz, P.W. \& Scheuthle, H., The theory of planned behaviour without compatibility? Beyond method bias and past trivial. Journal of Applied Social Psychology, 37(7), 1522-1544, 2007.

[4] McDonald, F.V., Developing an integrated conceptual framework of proenvironmental behaviour in the workplace through synthesis of the current literature. Administrative Sciences, 4, pp. 276-303, 2014.

[5] Kollmuss, A. \& Agyeman, J., Mind the gap: why do people act environmentally and what are the barriers to pro-environmental behaviour? Environmental Educ. Research, 8(3), pp. 241-260, 2002.

[6] Snyman, S.L., The role of tourism employment in poverty reduction and community perceptions of conservation and tourism in southern Africa. Journal of Sustainable Tourism, 20(3), pp. 395-416, 2012.

[7] Lundberg, E., The level of tourism development and resident attitudes: a comparative study of coastal destinations. Scandinavia Journal of Hospitality \& Tourism, DOI: 10.1080/1522250.2015.1005335, 2015.

[8] Stem, C.J., Lassoie, J.P., Lee, D.R., Deshler, D.D. \& Schelhas, J.W., Community participation in ecotourism benefits: the link to conservation practices and perspectives. Society and Natural Resources: An International Journal, 16(5), pp. 387-413, 2003.

[9] Stronza, A., The economic promise of ecotourism for conservation. Journal of Ecotourism, 6(3), pp. 210-230, 2007.

[10] McKenzie-Mohr, D. \& Schultz, P.W., Choosing effective behaviour change tools, A paper presented at the Behaviour, Energy and Climate Change Conference, Sacramento, California, 2012.

[11] Ajzen, I., The theory of planned behaviour. Organizational Behaviour and Human Decision Processes, 50, pp. 179-211, 1991.

[12] Fishbein, M. \& Ajzen, I., Belief, attitude, intention and behaviour: an introduction to theory, Addison-Wesley: Reading, MA, 1975.

[13] Lwoga, N.B., Anderson, W., Mapunda, B., Andersson, T.D. \& Mossberg, L., Socio-psychological motives for stakeholders' engagement in conservation of built heritage attractions in Tanzania. Proc. of the ATLAS Africa Conference on Tourism and Inclusive Growth in Developing Economies, ATLAS: Dar es Salaam, pp. 8-15, 2015.

[14] Barr, S. \& Gilg, A., A conceptual framework for understanding and analyzing attitudes towards environmental behaviour. Human Geography, 89(4), pp. 361-379, 2007. 
[15] Tang, Z., Chen, X. \& Luo, J., Determining socio-psychological drivers for household recycling behaviour in developing countries: a case study from Wugan, China. Environment \& Behaviour, 43(6), pp. 848-877, 2011.

[16] Wells, M., Brandon, K.E. and Hannah, L., People and parks: linking protected area management with local communities. World Bank: Washington, DC, 1992.

[17] Skinner, B.F., Selection by consequences. Science, 213(4507), pp. 501504, 1981.

[18] Mapunda, B., Destruction of archaeological heritage in Tanzania: The cost of ignorance. Trade in illicit antiquities: The destruction of the world's archaeological heritage, ed. N. Brodie, J. Doole \& C. Renfrew, McDonald Institute: Cambridge, pp. 47-56, 2001.

[19] Timothy, D.J. \& Nyaupane, G.P., Cultural heritage and tourism in the developing world: A regional perspective. Routledge: London, 2009.

[20] Clark, W.A. \& Finley, J.C., Determinants of water conservation intention in Blagoevgrad, Bulgaria. Society and Natural Resources: An International Journal, 20(7), pp. 613-627, 2007.

[21] Abrahamse, W. \& Steg, L., Factors related to household energy use and intention to reduce it: the role of psychological and demographic variables. Human Ecology Review, 18(1), pp. 30-40, 2011.

[22] Tonglet, M. Phillips, P.S. \& Read, A.D., Using the theory of planned behaviour to investigate the determinants of recycling behaviour: a case study from Brixworth, UK. Resources Conservation and Recycling, 41, pp. 191-214, 2004.

[23] Kankpeyeng, B.W., The cultural landscape of Tongo-Tenzuk, Ghana, In Joffroy, T (Ed.) Traditional conservation practices in Africa. ICCROM Conservation Studies: Rome, pp. 16-23, 2009.

[24] Napon, A. \& Rakotomamonjy, B., The Na-Yiri of Kokologho, Burkina Faso. In Joffroy, T (Ed.). Traditional conservation practices in Africa, ICCROM Conservation Studies: Rome, pp. 6-15, 2009.

[25] Zanzibar Commission for Tourism [ZCT], Zanzibar destination: five years marketing plan (2015-2020). Online. http://www.zati.org/wpcontent/up loads/2014/12/MPLANLAST-2015-2020.pdf, 2014.

[26] United Republic of Tanzania [URT], Extending the coastal forest protected area subsystem in Tanzania, n.d. Online http://www.tz.undp.org /content/dam/tanzania/Extending $\% 20$ the $\% 20$ coastal $\% 20$ forest $\% 20$ protected $\% 20$ areas $\% 20$ subsytem $\% 20 \mathrm{in} \% 20$ Tanzania.pdf

[27] United Republic of Tanzania [URT], 2012 Population and Housing Census, National Bureau of Statistics: Dar es Salaam, 2013.

[28] Hair, J.F., Black, W.C., Babin, B.J. \& Anderson, R.E., Multivariate data analysis. Pearson Education Limited: London, 2014.

[29] Ajzen, I., Construction of a theory of planned behaviour questionnaire, Measurement database for social science, 2013. Online. www.midss.ie

[30] Nunnally, J., Psychometric Theory, New York, NY: McGraw-Hill, 1978. 
[31] Fornell, C. and Larcker, D.F., Evaluating structural equation models with unobservable variables and measurement error. Journal of Marketing Research. 18, pp. 39-50, 1981.

[32] Kusimba, C.M., Kenya's destruction of Swahili heritage. Plundering Africa's past: the erasure of cultural patrimony, ed. P.R. Schmidt, \& R. McIntosh, Indiana University Press: Bloomington, pp. 201-224, 1996. 